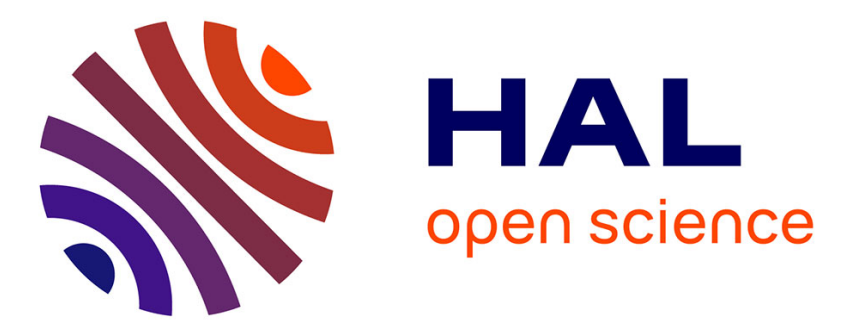

\title{
Comment on "Transition to the Relativistic Regime in High Order Harmonic Generation"
}

F. Quéré, Cédric Thaury, J-P. Geindre, Ph. Martin

\section{To cite this version:}

F. Quéré, Cédric Thaury, J-P. Geindre, Ph. Martin. Comment on "Transition to the Relativistic Regime in High Order Harmonic Generation". Physical Review Letters, 2008, 100 (8), pp.089401. 10.1103/PhysRevLett.100.089401 . hal-01166808

\section{HAL Id: hal-01166808 \\ https://hal.science/hal-01166808}

Submitted on 17 Jul 2015

HAL is a multi-disciplinary open access archive for the deposit and dissemination of scientific research documents, whether they are published or not. The documents may come from teaching and research institutions in France or abroad, or from public or private research centers.
L'archive ouverte pluridisciplinaire HAL, est destinée au dépôt et à la diffusion de documents scientifiques de niveau recherche, publiés ou non, émanant des établissements d'enseignement et de recherche français ou étrangers, des laboratoires publics ou privés. 


\section{Comment on "Transition to the Relativistic Regime in High Order Harmonic Generation"}

In [1], Tarasevitch et al. demonstrate the existence of two generation mechanisms for laser high-order harmonics from overdense plasmas. One of these mechanisms leads to harmonics with frequencies up to the maximum plasma frequency $\omega_{p}$ of the target and occurs even at nonrelativistic laser intensities. We show that the mechanism responsible for these harmonics is coherent wake emission (CWE) [2,3], a process that significantly differs from the qualitative model proposed by these authors, and it leads to a different interpretation of several essential features of this emission.

Figure 1 shows the result of a particle-in-cell (PIC) simulation, where a $p$-polarized laser field, with a normalized vector potential $a_{0}=0.2$, impinges an overdense plasma with an incidence angle of $45^{\circ}$. Ions are assumed to be fixed, and an exponential density gradient of scale length $L=0.02 \lambda$ is imposed at the surface. This figure reveals the main features of CWE. High-frequency plasma oscillations (PO's) are impulsively excited in the highly overdense part of the plasma, once every optical cycle, in the wake of ultrashort energetic electron bunches created by the laser field around the critical density $n_{c}$. These PO's emit extreme ultraviolet light through linear mode conversion, in the form of one chirped attosecond pulse once every optical cycle, thus resulting in a spectrum consisting of harmonics of the laser field.

The authors of [1] state that this harmonic emission occurs when electrons that "are pushed back and forth in the gradient of charge density" have an oscillation amplitude $s_{0}$ comparable to the gradient scale length $L$, resulting in a "motion that is strongly anharmonic". On the contrary, the CWE model, clearly supported by PIC simulations, shows that in this regime the anharmonicity of the plasma surface motion is irrelevant. PO's observed on Fig. 1 are linear, and the intensity of the emitted harmonics scales almost linearly with the laser intensity (Fig. 1 in [2]).

CWE provides a direct interpretation of the sharp cutoffs observed at $\omega_{p}$ both on simulated and experimental harmonic spectra [1-3], independently of the laser intensity (below the relativistic regime), since in this mechanism the maximum harmonic frequency is determined by the maximum plasma density. This is not the case of the model proposed in [1], which, according to Eq. (14) of [4], would lead to an emission that tends to 0 only when $\omega \gg \omega_{p}$, i.e., to a smooth roll-off beyond $\omega_{p}$. This roll-off should moreover strongly depend on the parameter $s_{0} / L$, and hence on the laser intensity.

Tarasevitch et al. show that this harmonic emission decreases when the gradient scale length gets too long. Their interpretation is that for long gradients, the laser field

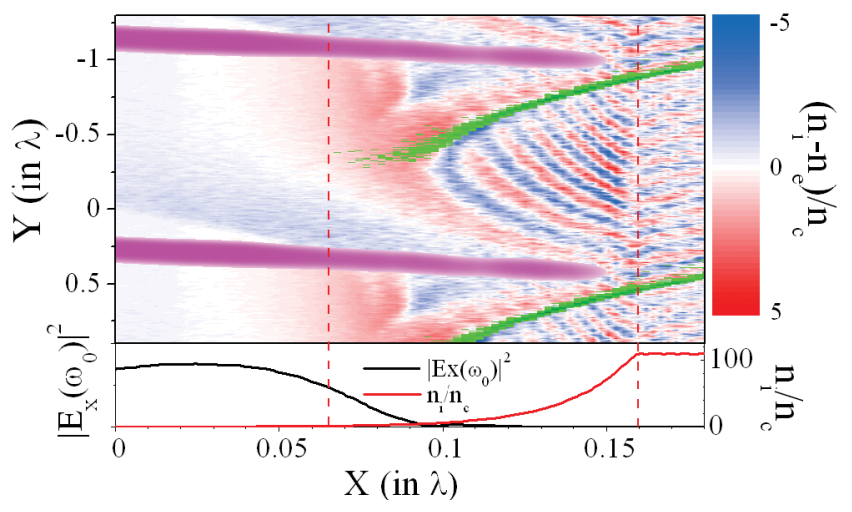

FIG. 1 (color). PIC simulation of coherent wake emission. The upper panel shows the total charge density (blue to red scale) $n_{i}-n_{e}$, the energetic $\left(p_{x}>0.15 m c\right)$ electron density (green scale), and the electromagnetic field frequency-filtered from harmonics 4 to 10 (purple scale). The lower panel shows $\left|E_{x}\left(\omega_{L}\right)\right|^{2}$ ( $\omega_{L}$ being the laser frequency) in black, and the ion density profile in red. The dashed lines indicate the positions of $n_{c}$ and $110 n_{c}$.

fails to "penetrate far enough into the plasma". Figure 1 (lower panel) shows that even when this emission does occur, the laser field does not penetrate the density gradient beyond a few $n_{c}$, and is hence absolutely negligible in the area where the harmonics are emitted, thus ruling out this interpretation. In CWE, in analogy with resonant absorption of laser light, each harmonic frequency $p \omega_{L}$ forms an evanescent wave between its point of generation, at $n=$ $p^{2} n_{c}$, and $n=p^{2} n_{c} \cos ^{2} \theta$ ( $\theta$ being the laser angle of incidence), where it becomes a progressive wave and escapes the plasma. Since the distance between these two points increases with the gradient scale length, this accounts for the decrease in efficiency for long density gradients.

\footnotetext{
F. Quéré, ${ }^{1}$ C. Thaury, ${ }^{1}$ J-P. Geindre, ${ }^{2}$ and Ph. Martin ${ }^{1}$

${ }^{1}$ SPAM

Commissariat à l'Energie Atomique

CEN Saclay, 91191 Gif sur Yvette, France

${ }^{2}$ LULI

UMR 7605-CNRS-CEA-Ecole Polytechnique-Paris VI

F91128 Palaiseau, France
}

Received 22 March 2007; published 27 February 2008

DOI: 10.1103/PhysRevLett.100.089401

PACS numbers: 42.65.Ky, 52.27.Ny, 52.38. - r, 52.65.Rr

[1] A. Tarasevitch, K. Lobov, C. Wünsche, and D. von der Linde, Phys. Rev. Lett. 98, 103902 (2007).

[2] F. Quéré et al., Phys. Rev. Lett. 96, 125004 (2006).

[3] C. Thaury et al., Nature Phys. 3, 424 (2007).

[4] B. Bezzerides, R. D. Jones, and D. W. Forslund, Phys. Rev. Lett. 49, 202 (1982). 